\title{
Rotary bending as a mean for improving micro-cleanliness of stainless steels for high demanding applications
}

\author{
Thomas Sourisseau ${ }^{1, *}$, Dominique Ferrière ${ }^{1}$, Frédéric Moser $^{1}$, Maximilien Libert ${ }^{1}$, Pierre Chemelle ${ }^{1}$, and Christian Deville- \\ Cavellin ${ }^{1}$
}

${ }^{1}$ Research Center, UGITECH, avenue Paul Girod, 73403 UGINE Cedex, France

\begin{abstract}
Stainless steels are used for automotive or medical applications which require a high fatigue resistance correlated to a high level of micro-cleanliness. A methodology based on rotary bending tests carried out on wires or bars has been defined to determine the material's endurance limit (after 100 millions cycles) and identify the largest subcutaneous inclusions or precipitates where failures initiate. This methodology has been applied to EN 1.4568 spring wires. Failures were found to initiate both at oxide inclusions and $A l N$ precipitates. For the same size, $A l N$ precipitates were observed to be more critical towards crack initiation than oxide inclusions, due to their angular shape and lower thermal expansion at high temperatures. However, oxide inclusions larger than the AlN maximum size strongly impact the material's fatigue limit, and their density and size should be reduced.
\end{abstract}

\section{Introduction}

Austenitic stainless steel wires and bars are used in a wide range of applications which require both corrosion resistance and mechanical properties. For some specific applications like medical implants (mainly EN 1.4441 or EN 1.4472 stainless steel grades) or springs dedicated to automotive injectors (where EN 1.4568 stainless steel grade is used), they also have to sustain very high cycle (100 millions or more) fatigue phenomena in moderately aggressive environments. Hence, the endurance limit of those materials (which may be defined as the maximum stress below which the material may sustain an infinite number of cycles) should be optimized to support high pressures.

This characteristic is closely related to bar or wire surface finish (i.e. roughness and presence of geometrical surface irregularities on one hand, residual stresses due to surface work-hardening on the other hand) as well as its mechanical properties ${ }^{[1]}$. Several authors ${ }^{[1-2]}$ have proposed relationships between endurance limit $\left(\sigma_{D}\right.$ in MPa), tensile strength $\left(R_{m}\right.$ in $\mathrm{MPa})$, yield strength $\left(\mathrm{Rp}_{0.2}\right.$ in $\left.\mathrm{MPa}\right)$ and elongation at break (A in \%) of steels. Equation (1) can be used in the case of a large range of steels and stainless steels to roughly estimate the value of $\sigma_{\mathrm{D}}{ }^{[1]}$ :

$$
\sigma_{D}=0.41 R_{m}+2 A
$$

High tensile strengths (up to $1700 \mathrm{MPa}$ and more) can be achieved on targeted austenitic stainless steels like EN 1.4568 by a combination of:

- $\quad$ high carbon content,

- metastable austenite, converted into hard martensite by work-hardening during wire-drawing,
- precipitation hardening (by a heat treatment at $480^{\circ} \mathrm{C}$ ) which makes $\mathrm{NiAl}$ precipitate within the martensite.

Beside mechanical properties and surface finish, the high cycle fatigue resistance of stainless steels is strongly correlated to their micro-cleanliness, and mostly to inclusion morphologies and sizes, inclusion locations and compositions, elastic and plastic properties of inclusions relatively to those of the surrounding matrix, and finally adhesion between inclusions and matrix ${ }^{[1][3-8]}$. Those effects are particularly enlightened in the case of automotive springs whose surfaces have been either machined or shaved to remove surface defects and lower their roughness.

Inclusions mainly lower fatigue resistance by increasing stresses in their surrounding area which is then work-hardened. Micro-cracks may initiate either by tearing of inclusion/matrix interfaces, or at the periphery of those work-hardened areas ${ }^{[1]}$. Inclusion size is of prime importance ${ }^{[1,3,8]}$, but its effect strongly depends on the level of applied stresses. In oligocyclic fatigue, micro-cracks may initiate at numerous small inclusions, due to high applied stresses, which makes failure follow preferentially a way passing near those small but close one to another inclusions, in the maximum stress area. Hence, high dispersions of small inclusions must be avoided if a high oligocyclic fatigue resistance is targeted. On the opposite, for high cycle fatigue with low applied stresses, the biggest inclusions are most harmful, since they are preferential sites for crack initiation, those cracks propagating until final fracture occurs ${ }^{[1]}$.

For high cycle fatigue, MURAKAMI ${ }^{[3,8]}$ has observed that the endurance limit of a material is not necessarily

Corresponding author: thomas.sourisseau@ugitech.com 
correlated to the results of standard micro-cleanliness quotations (according to ASTM E45 or ISO 4967 for example) and has found relationships between the fatigue limit $\sigma_{\mathrm{D}}(\mathrm{MPa})$ of the material, its hardness $\mathrm{Hv}$ $\left(\mathrm{kgf} / \mathrm{mm}^{2}\right)$ and the parameter $\sqrt{A_{\max }}(\mu \mathrm{m})$, where $\mathrm{A}_{\max }$ is equal to the area of the largest inclusion projected on the plan perpendicular to maximum main stress. In the case where the largest inclusion is subcutaneous or internal, the following equation has been proposed:

$$
\sigma_{D}=\frac{1.56\left(H_{v}+120\right)}{(\sqrt{A})^{1 / 6}}
$$

MURAKAMI has also defined a methodology $[3,8]$ based on Extreme Value Method and rotary bending tests, which determines the value of $\mathrm{A}_{\max }$ in a given volume of material.

Based on this approach, the present work aims at setting up rotary bending equipment adapted to wires or bars, and defines protocols for sample preparation and test parameter calculation. Finally, this methodology was applied to determine the material's fatigue limit and also identify the largest subcutaneous precipitates formed in EN 1.4568 spring wires used for demanding automotive applications, for which a high fatigue resistance is requested. The analysis of the largest inclusions should help understanding the mechanism of their formation and hence proposing solutions to improve the endurance limit of the material by reducing the density of those inclusions.

\section{The rotary bending equipment}

Rotary bending machines may belong to two main types, depending on the evolution of the applied moment along the sample:

- those with a linear moment in relation to a twopoint bending system; in this case, applied stress is maximum at the middle of the sample;

- those with a constant moment along a part of the sample, thanks to a three- or four-point bending system.

The equipment used in this study is a four-point bending system which aims at applying a constant moment at the surface of a stainless steel wire over a length of $200 \mathrm{~mm}$ (which is close to the length of current injector springs). The volume of tested material also corresponds to the first superficial millimeter of the wire over a length of $200 \mathrm{~mm}$ (see figure 1). Testing 20 samples along a coil or a batch of bars gives a tested volume which can be representative of the complete coil or batch ${ }^{[3,8]}$.

Standard rotary bending machines are not able to test such long samples. Moreover, the other originality of this equipment comes from its ability to test a sample of stainless steel wire or bar with its industrial surface state, unlike standard benches whose samples are machined.

Figure 2 shows a general view of the rotary bending equipment which has been supplied by ZARIAN GmbH. Wire or bar samples of diameters between 2 and $7 \mathrm{~mm}$ can be tested, which is not the case with standard equipment. The sample is mounted in a jaw and turns at a constant frequency thanks to a $2,5 \mathrm{~kW}$ brushless engine. This latter is set on a platform which can freely rotate to avoid any unexpected additional bending nor twisting of the sample.

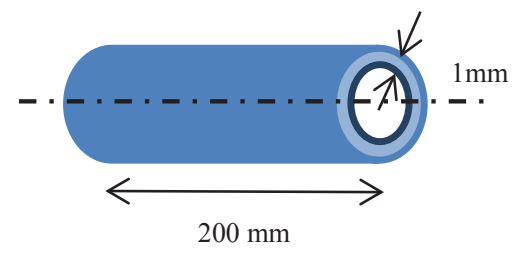

Fig. 1. Sample tested volume

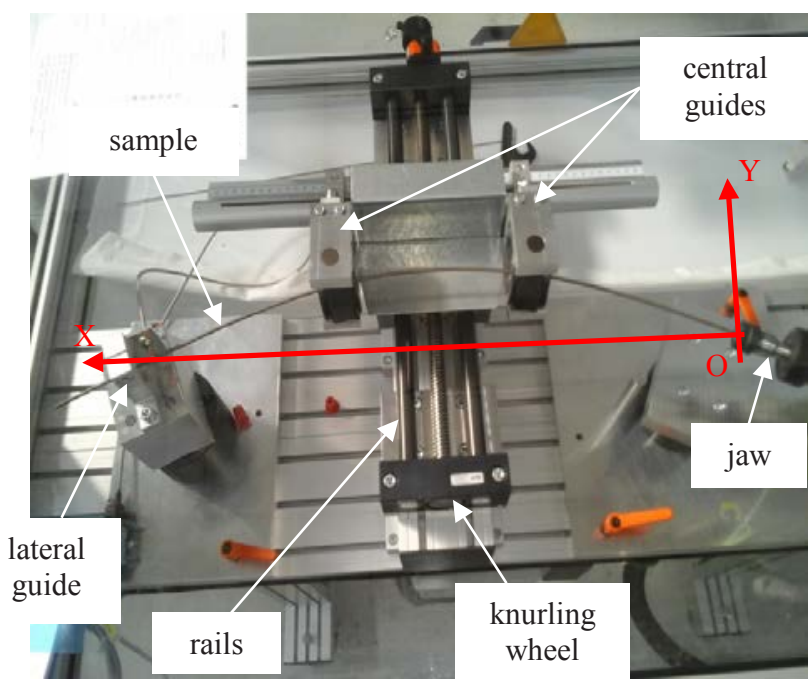

Fig. 2. Rotary bending machine for stainless steel wires

Two central guides may translate along both $\mathrm{X}$ and $\mathrm{Y}$ axis (on rails), and one lateral guide (at the sample extremity) may translate along $\mathrm{X}$ axis (see figure 2). Their positions, which can be precisely measured by verniers, give the targeted curvature to the sample. Positions of central guides along $\mathrm{Y}$ axis are set by a knurling wheel. Initial alignment of both the three guides and the jaw (when no curvature is applied to the sample) has been checked to avoid any bias in the test results.

Furthermore, a gauge set on the engine counts the number of sample rotations and both engine and counting stop when the sample breaks (via a laser detector placed near the lateral guide which detects when sample end stops moving) or when the targeted number of cycles (i.e. 100 millions) is reached.

Among the most critical points are the conditions of contact between sample and the three guides. These latters should keep friction as low as possible in order to avoid sample twisting and heating. This is achieved by using seals of specific material and internal diameter. Finally, seal length has been optimized to minimize additional bending of the sample in those contact zones.

\section{Preparation and characterization}


Trials have been carried out with $3.60 \mathrm{~mm}$ diameter drawn wire of grade EN 1.4568, produced by UGITECH from wire-rod coils.

\subsection{Chemical analysis and wire-rod metallurgy}

Chemical analysis of the tested material is given in table 1. Blooms have been hot-rolled into wire-rod coils which have been then shaved and drawn to final diameter $3.60 \mathrm{~mm}$.

Table 1. Chemical analysis of EN 1.4568 samples

\begin{tabular}{|c|c|c|c|c|c|c|c|c|c|c|}
\hline & $\mathrm{C}$ & $\mathrm{Si}$ & $\mathrm{Mn}$ & $\mathrm{Ni}$ & $\mathrm{Cr}$ & $\mathrm{Mo}$ & $\mathrm{S}$ & $\mathrm{P}$ & $\mathrm{Cu}$ & $\mathrm{Al}$ \\
\hline EN 10088-3 & $\leq 0,090$ & $\leq 0,7$ & $\leq 1,0$ & $6,5-7,8$ & $16,0-18,0$ & - & $\leq 0,015$ & $\leq 0,040$ & - & $0,7-1,5$ \\
\hline
\end{tabular}

Grade EN 1.4568 solidifies as primary ferrite, and then transforms into austenite during hot-rolling, according to figure 5. Residual ferrite in wire-rod is less than $1 \%$. A typical austenitic microstructure of wire-rod is shown in figure 3 .

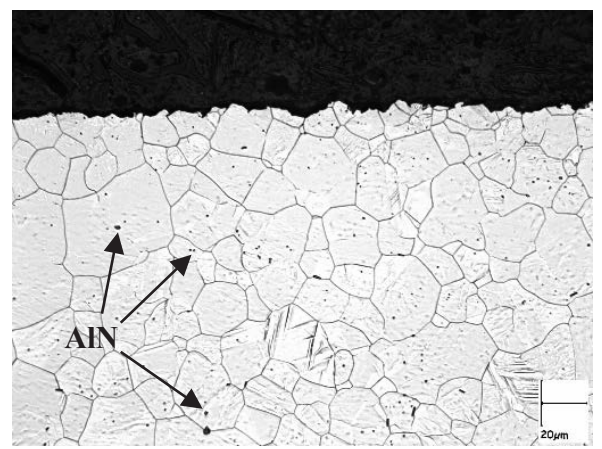

Fig. 3. Austenitic microstructure of EN 1.4568 wire-rod with dispersed $A l N$ precipitates

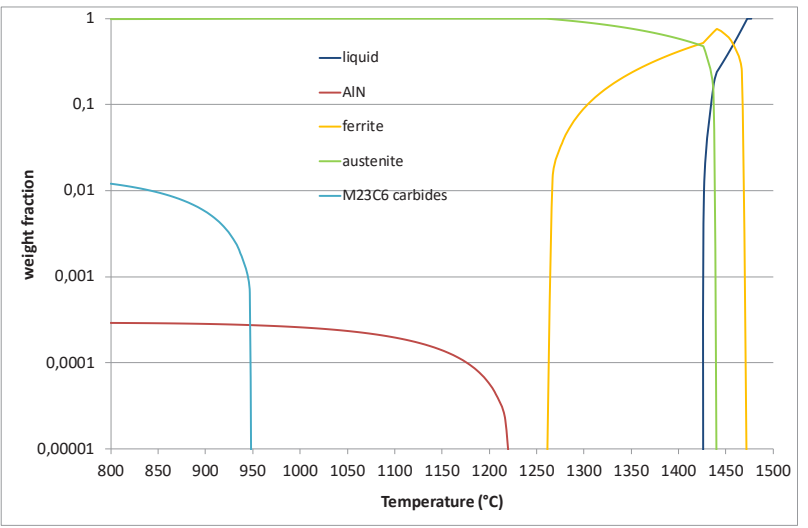

Fig. 4. Thermodynamic phase diagram of the studied EN 1.4568 material (according to Thermocalc $\AA$ calculations)

Since EN 1.4568 grade is characterized by a high Aluminium content, melting process has been carried out under conditions which should minimize Oxygen and Nitrogen contents. Indeed, Aluminium is very reactive towards these elements, leading to the formation of both oxide inclusions (before and during solidification) as well as $A l N$ precipitates which appear below $1230^{\circ} \mathrm{C}$, once material has been completely solidified, according to figure 4. Even if Oxygen and Nitrogen contents are very low, oxide inclusions and $A l N$ precipitates have been observed on micrographs, as illustrated by figure 3 . Furthermore, Titanium content is also very low which prevents angulous Titanium nitrides (favoring crack initiation during fatigue) from appearing in the studied material.

\subsection{Preparation of drawn wire samples}

Surface preparation is a key point to get successful results with rotary bending testing. Since the objective of the present study is to analyze stainless steel microcleanliness and its influence on high cycle fatigue resistance, failures should initiate at subcutaneous inclusions (in the first superficial millimeter) and not at surface defects. The wire-rod coils were hence shaved to remove all the surface defects which might have been induced by hot-rolling. Since the shaved wire had a very smooth surface, it then underwent a second operation aiming at restoring a sufficient surface roughness for the following wire-drawing step. Indeed, this roughness helped carrying lubricant into the drawing die when the wire section was reduced, ensuring a good lubrication during wire-drawing and preventing new surface defects (like scratches) from appearing.

Wire-drawing gives high mechanical properties to the wire by work-hardening, which contributes to its high fatigue resistance. Regarding grade EN 1.4568, wire-rod is almost fully austenitic, but austenite turns into hard martensite during wire-drawing. Martensite contents up to $60 \%$ can be achieved on wires drawn with reduction rates close to $70 \%$, which makes tensile strength as high as $1500 \mathrm{MPa}$. This level of tensile strength is required to ensure sufficient spring stiffness.

$600 \mathrm{~mm}$ long samples have been cut in one coil of $3.60 \mathrm{~mm}$ diameter drawn wire of grade EN 1.4568. Those samples have been straightened with a block of straightener rolls in order to get a satisfying straightness. This latter was required to avoid inaccurate rotary bending results.

Furthermore, straightened samples have been heat treated for $1 \mathrm{~h}$ at $480^{\circ} \mathrm{C}$ in order to relax high internal stresses present in the martensitic phase, and to harden the material by precipitation of NiAl particles (whose size is of a few tens of nanometers) in the martensite. This hardening phenomenon gave additional 200 to $300 \mathrm{MPa}$ to the tensile strength of the drawn wire. This heat-treatment has been carried out under vacuum in order to avoid sample oxidation.

Finally, samples needed to be shot-peened to get compressive stresses at their surface in order to avoid failure initiation at the surface, since applied stresses are maximal at the wire surface during bending. A shotpeening apparatus, equipped with four identical nozzles (set at the four cardinal points) and with a sample driving system, has been specially designed by S.F.G.P. (Société Française de Grenaillage de Précontrainte) to shot-peen wire samples as homogeneously as possible on the whole wire periphery and over the whole sample length. Different shot-peening conditions (type of shot, nozzle pressure and Almen intensity, driving speed) have been tested and final conditions have been selected which 
optimized both compressive residual stresses and surface roughness.

Mechanical properties of the final samples have been measured by tensile testing at room temperature: the corresponding values have been compiled in table 2 . The Young modulus value of table 2 agrees with the decreasing of this parameter reported in the literature ${ }^{[9]}$ when the product is work-hardened. Martensite content was measured by saturation magnetization and found equal to $58 \%$.

Table 2. Tensile properties of studied EN 1.4568 samples

\begin{tabular}{|c|c|c|c|}
\hline $\begin{array}{c}\text { Tensile } \\
\text { strength } \mathbf{R}_{\mathrm{m}} \\
(\mathbf{M P a})\end{array}$ & $\begin{array}{c}\text { Yield } \\
\text { strength } \\
\mathbf{R p}_{\mathbf{0 , 2}} \text { (MPa) }\end{array}$ & $\begin{array}{c}\text { Elongation at } \\
\text { break } \\
\mathbf{A}(\%)\end{array}$ & $\begin{array}{c}\text { YOUNG } \\
\text { modulus E } \\
(\mathbf{G P a})\end{array}$ \\
\hline 1656 & 1482 & 1 & 175 \\
\hline
\end{tabular}

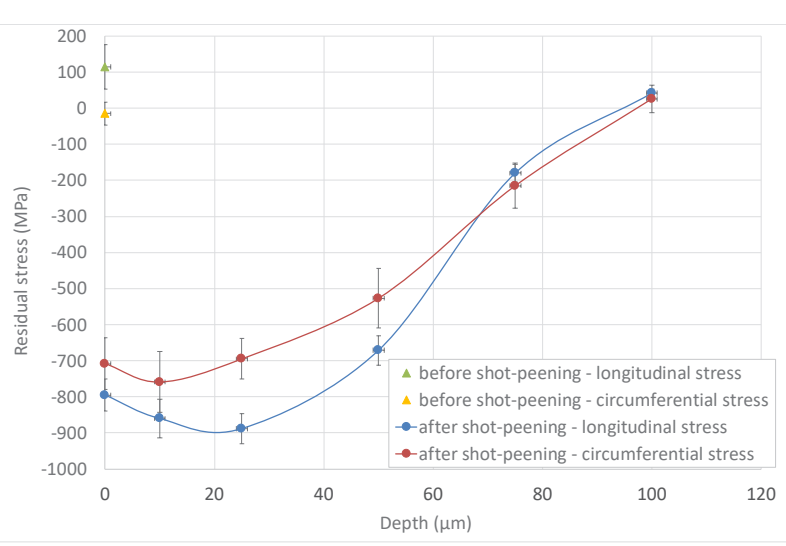

Fig. 5. Longitudinal and circumferential residual stresses measured by X-ray diffraction in the studied EN 1.4568 samples

Furthermore, sample roughness has been measured with a profilometer and a cut-off value equal to 17.5. Values of $R_{a}$ and $R_{z}$ (along the wire axis) have been found equal to respectively $1,8 \mu \mathrm{m}$ and $11 \mu \mathrm{m}$.

Finally, longitudinal and circumferential residual stresses have been measured on final samples with a Xray SEIFERT XRD3003 diffractometer and by $\sin ^{2}(\psi)$ method $^{[10]}$. For stress profiles, successive layers of material (of defined depths) have been removed by chemical dissolution of the material immersed in a $\mathrm{HNO}_{3} / \mathrm{HCl} / \mathrm{HF}$ electrolyte for variable times. Since measurements in austenite phase are not exploitable due to effects of preferential orientations, only measured values found in the martensite phase have been compiled ${ }^{[10]}$. Figure 5 shows that the pre-stressed depth is close to $80 \mu \mathrm{m}$, with maximum compressive stresses equal to respectively $-750 \mathrm{MPa}$ and $-900 \mathrm{MPa}$ for circumferential and longitudinal stresses, at a depth close to $20 \mu \mathrm{m}$. It is to be noticed that surface residual stresses of the drawn wire after heat treatment at $480^{\circ} \mathrm{C}$ and before final shot-peening are close to zero, meaning that complete relaxation occurred during heat treatment.

\section{Conditions of rotary bending tests}

Figure 6 describes a stressed sample (with diameter $\varnothing$ ) during a rotary bending test, with the theoretical profile of applied bending moment. Positions $\mathrm{A}$ and $\mathrm{C}$ represent contact points between sample and central guides. Sample deflection is maximal at point B (sample half length).

Since targeted samples are round with rather low diameters, measurement of applied stresses at sample surface with a strain gauge is difficult, so that applied stresses need to be calculated from the sample curvature.

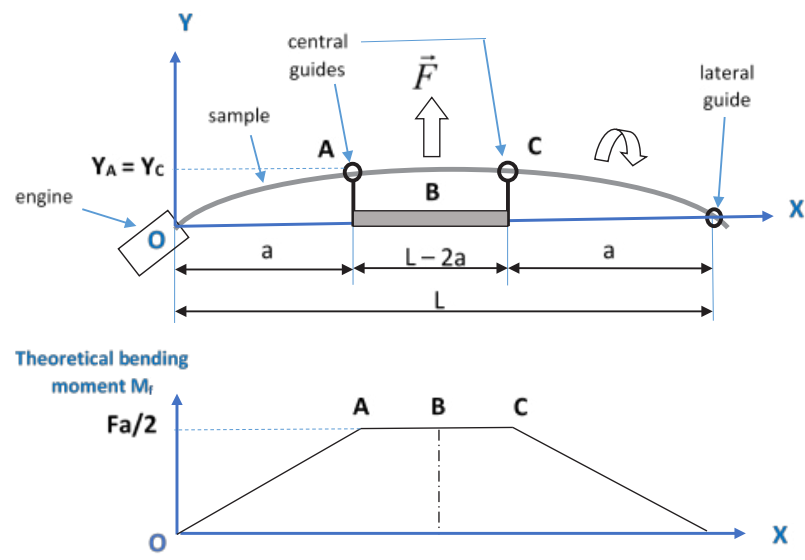

Fig. 6. Applied bending load F, and theoretical bending moment $\mathrm{M}_{\mathrm{f}}$ during a rotary bending test

In this study, rotary bending tests have been carried out with a $3.60 \mathrm{~mm}$ diameter sample of EN 1.4568 grade with a length $\mathrm{L}$ equal to $600 \mathrm{~mm}$, bent with different $\mathrm{y}_{\mathrm{A}}$ values (positions of both central guides along $\mathrm{Y}$ axis) ranging from 55 to $95 \mathrm{~mm}$, and with a constant value of $\mathrm{a}=200 \mathrm{~mm}$ (see figure 6). Rotating speed was constant and equal to $4500 \mathrm{rpm}$.

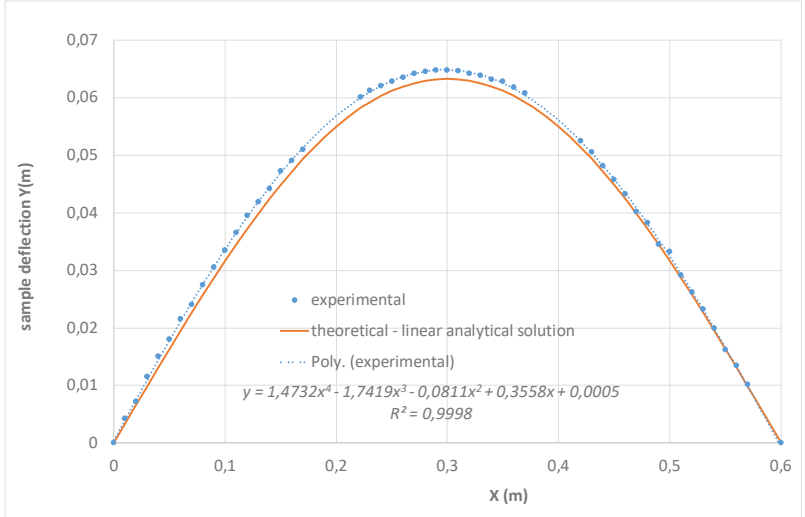

Fig. 7. Comparison between experimental and theoretical profiles $y(x)$ of $3.60 \mathrm{~mm}$ diameter stainless steel samples bent with $\mathrm{y}_{\mathrm{A}}=55 \mathrm{~mm}$

For a given $\mathrm{y}_{\mathrm{A}}\left(\right.$ or $\left.\mathrm{y}_{\mathrm{C}}\right)$ value, calculation of the testing parameters (bending moment and load, maximum and minimum applied stresses) requires the following steps, according to M. AYADA and $\mathrm{al}^{[11]}$.

$1 /$ measurement of the sample deflection $\mathrm{y}(\mathrm{x})$ along its length; example of measurements obtained for $\mathrm{y}_{\mathrm{A}}=55 \mathrm{~mm}$ have been reported on figure 7;

2/ calculation of the resultant bending load $F$ by minimization of the potential energy (sum of the work of load $\mathrm{F}$ and sample deformation energy) which gives the following relationship between load $\mathrm{F}(\mathrm{N})$ and maximum deflection $\mathrm{y}_{\mathrm{B}}(\mathrm{m})$ at point $\mathrm{B}^{[11]}$. 


$$
F=E I \alpha y_{B}\left[1+\beta y_{B}^{2}+\lambda y_{B}^{4}\right]
$$

where:

$\mathrm{E}(\mathrm{GPa})$ is the sample YOUNG modulus;

$\mathrm{I}\left(\mathrm{m}^{-4}\right)$ is the sample moment of inertia of area;

$\alpha, \beta$ and $\lambda$ are L- and a- dependent parameters.

$3 /$ calculation of reaction forces $\mathrm{N}_{1}$ and $\mathrm{N}_{2}$ on the one hand, friction forces $\mu \mathrm{N}_{1}$ and $\mu \mathrm{N}_{2}$ on the other hand ( $\mu$ being the friction coefficient) at contact points $\mathrm{O}$ (between sample and jaw) and A (between sample and central guide), according to figure 8 . Those forces can be deduced from the force equilibrium equation projected on $\mathrm{X}$ and $\mathrm{Y}$ axis, which gives the following relationships:

$$
\begin{aligned}
& N_{1}=\frac{F}{2\left(\cos \theta_{1}+\mu \sin \theta_{1}\right)} \\
& N_{2}=\frac{F}{2\left(\cos \theta_{2}-\mu \sin \theta_{2}\right)}
\end{aligned}
$$

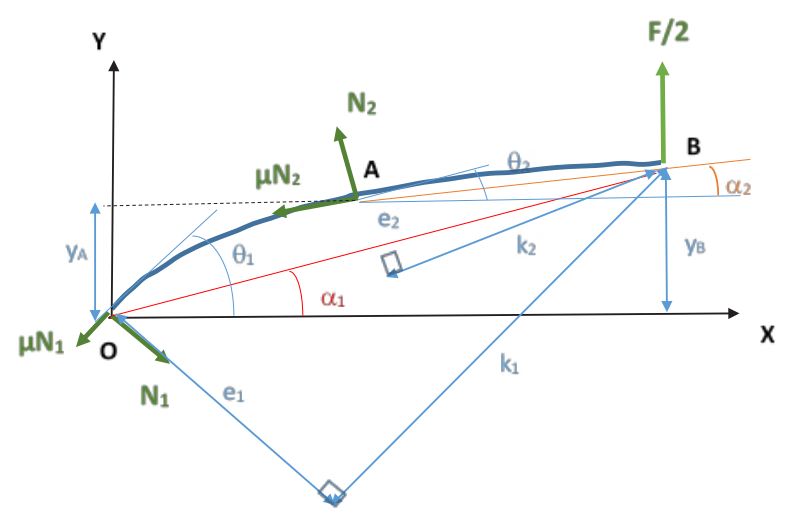

Fig. 8. Description of the loading system during rotary bending test (first half of sample length)

4/ calculation of the global bending moment $M_{B}$ applied at point $\mathrm{B}$, equal to the sum of the bending moments of the contact forces $\mathrm{N}_{1}, \mathrm{~N}_{2}, \mu \mathrm{N}_{1}$ and $\mu \mathrm{N}_{2}$ :

$$
M_{B}=N_{1} k_{1}+\mu N_{1} e_{1}-N_{2} k_{2}+\mu N_{2} e_{2}
$$

where $\mathrm{k}_{1}, \mathrm{k}_{2}, \mathrm{e}_{1}$ and $\mathrm{e}_{2}$ are geometrical parameters deduced from the measured sample profile according to figure 8;

5/ finally, determination of maximum applied stress $\mathrm{S}_{\max }$ (at sample extrado) and minimum applied stress $\mathrm{S}_{\min }$ (at sample intrado), both calculated at sample halflength (point B), thanks to the following relationships:

$$
\begin{aligned}
& S_{\max }=\frac{M_{B} \phi}{2 I}+\frac{4 H}{\pi \phi^{2}} \\
& S_{\min }=\frac{-M_{B} \phi}{2 I}+\frac{4 H}{\pi \phi^{2}}
\end{aligned}
$$

where $\mathrm{H}$ is the global force resulting from the different contact and friction forces, equal to :

$$
H=\mu N_{1} \cos \theta_{1}-N_{1} \sin \theta_{1}+\mu N_{2} \cos \theta_{2}+N_{2} \sin \theta_{2}
$$

It has to be pointed out that no sample heating has been observed during rotary bending test, even near the contact points with the central guides, showing that friction coefficient $\mu$ is very low. A value $\mu=0,02$ corresponding to a very well lubricated contact has also been chosen for all the calculations reported in this article.

Furthermore, sample profile can be calculated by the linear analytical method (under small deflections), by double integrating the theoretical bending moment (represented in figure 6), and by considering that this moment is constant between the central guides. Under those assumptions, sample profile $\mathrm{y}(\mathrm{x})$ follows polynomial functions:

$$
y(x)=\frac{6 y_{A}}{a^{2}(3 L-4 a)}\left[\frac{x^{3}}{6}-a\left(\frac{L}{2}-\frac{a}{2}\right) x\right] \quad \text { if } \mathrm{x} \in[0 ; \mathrm{a}]
$$

and:

$$
y(x)=\frac{6 y_{A}}{a(3 L-4 a)}\left[\frac{x^{2}}{2}-\frac{L}{2} x+\frac{a^{2}}{6}\right] \text { if } \mathrm{x} \in\left[\mathrm{a} ;\left(\frac{L}{2}-\mathrm{a}\right)\right]
$$

However, experimental measurements of sample profiles are best fitted with a 4-order polynomial function (see figure 7) and some differences between experimental and theoretical profiles may become significant for high deflections. Moreover, the linear analytical approach may engender discrepancies in the calculation of maximum and minimum applied stresses in comparison to those based on experimental measurement of sample profile (discrepancies which become significant for high deflections), as shown in table 3. For this reason, values of $S_{\max }$ reported in the following paragraphs have been calculated based on

\begin{tabular}{|c|c|c|c|c|c|c|c|c|}
\hline \multirow{2}{*}{$\begin{array}{c}Y_{A} \\
(m m)\end{array}$} & \multicolumn{2}{|c|}{$y_{B}-y_{A}(m m)$} & \multicolumn{2}{|c|}{$\begin{array}{l}\mathrm{S}_{\max }(\mathrm{MPa}) \text { at sample } \\
\text { half-length (point } \mathrm{B} \text { ) }\end{array}$} & \multicolumn{2}{|c|}{$\begin{array}{l}\mathrm{S}_{\min }(\mathrm{MPa}) \text { at sample } \\
\text { half-length (point } \mathrm{B} \text { ) }\end{array}$} & \multicolumn{2}{|c|}{\begin{tabular}{|c|}
$\mathrm{S}_{\max }(\mathrm{MPa})$ at the \\
contact point between \\
sample and central \\
guide (point $\mathrm{A})$
\end{tabular}} \\
\hline & $\begin{array}{c}\text { by linear } \\
\text { analytical } \\
\text { method }\end{array}$ & $\begin{array}{l}\text { with } \\
\text { measured } \\
\text { sample } \\
\text { profile }\end{array}$ & $\begin{array}{c}\text { by linear } \\
\text { analytical } \\
\text { method }\end{array}$ & \begin{tabular}{|c|} 
with \\
measured \\
sample \\
profile
\end{tabular} & $\begin{array}{c}\text { by linear } \\
\text { analytical } \\
\text { method }\end{array}$ & $\begin{array}{l}\text { with } \\
\text { measured } \\
\text { sample } \\
\text { profile }\end{array}$ & $\begin{array}{c}\text { by linear } \\
\text { analytical } \\
\text { method }\end{array}$ & $\begin{array}{c}\text { with } \\
\text { measured } \\
\text { sample } \\
\text { profile }\end{array}$ \\
\hline 55 & 8,3 & 9,8 & 489 & 503 & -490 & -504 & 487 & 500 \\
\hline 65 & 9,8 & 11,3 & 572 & 583 & -572 & -583 & 568 & 578 \\
\hline 85 & 12,8 & 14,0 & 755 & 772 & -756 & -773 & 746 & 761 \\
\hline 95 & 13,8 & 15,5 & 876 & 942 & -877 & -944 & 862 & 921 \\
\hline
\end{tabular}
measured sample profiles.

Finally, despite those differences, table 3 shows that $\mathrm{S}_{\max }$ values are almost constant between points $\mathrm{A}$ and $\mathrm{B}$, which means that this parameter is almost constant in the sample part located between both central guides.

Table 3. Values of rotary bending parameters calculated by the linear analytical approach or by experimental measurement of sample profile

\section{Results of rotary bending tests and inclusion analyzes}

The results of rotary bending tests carried out on $3.60 \mathrm{~mm}$ diameter samples of EN 1.4568 grade are shown in WÖHLER's curve of figure 9.

Over the 25 sample failures observed during the trials, only three initiated at sample surface, showing that the material preparation is adapted to the testing conditions. The other failures have initiated at subcutaneous inclusions or precipitates, located in the 
first $0.5 \mathrm{~mm}$ of sample depth. Particles have been analyzed with a JEOL 7001F SEM, equipped with a SDD-EDX analyzer, run at $15 \mathrm{kV}$. Two populations of particles have been identified as initiating sites (see figure 10):

- $\quad$ Aluminium nitrides whose sizes lay between 5 and $9 \mu \mathrm{m}$ and which represent the majority of the cases;

- oxide inclusions whose sizes can reach up to $23 \mu \mathrm{m}$ and which represent about $20 \%$ of the observed particles.

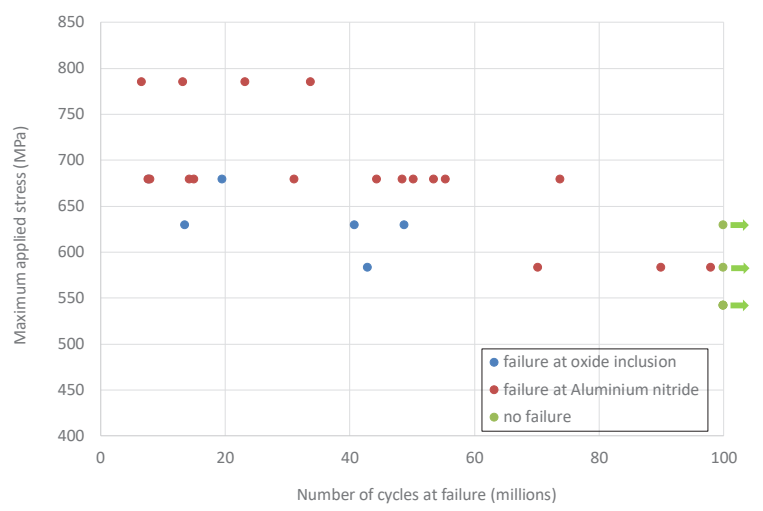

Fig. 9. Results of rotary bending tests carried out on $3,60 \mathrm{~mm}$ diameter drawn wires of EN 1.4568 grade

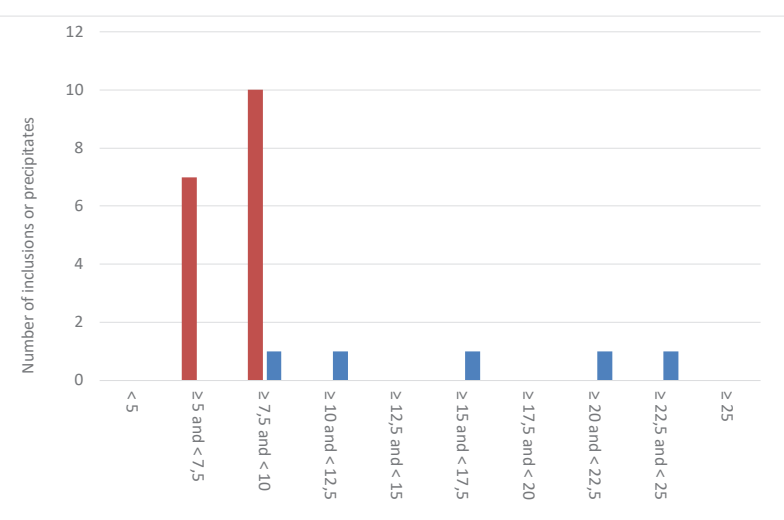

Fig. 10. Size distribution of particles observed after rotary bending tests carried out on EN 1.4568 drawn wire

Oxide inclusions have rather globular shapes whereas AlN are more flat and angulous, according to figures 11 and 12. SEM observations combined with XRay analyzes and mapping have shown that oxide inclusions are complex and multiphase oxides, with high global contents of both $\mathrm{Al}_{2} \mathrm{O}_{3}$ and $\mathrm{CaO}$, but also containing $\mathrm{MgO}$ in variable amounts (from $0.5 \%$ up to $75 \%$ ) depending on the analyzed area of the same inclusion (see figure 12). Some inner or outer parts are locally enriched in $\mathrm{MgO}$. Global contents of those inclusions are close to that of $\mathrm{C}_{12} \mathrm{~A}_{7}$ compound.

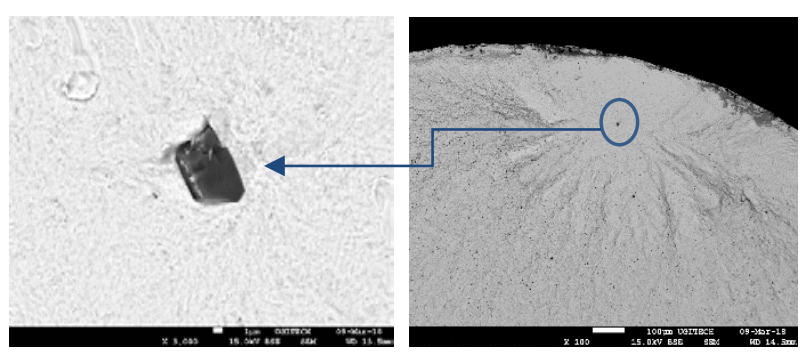

Fig. 11. Typical Aluminium nitride precipitate identified as failure initiation site during rotary bending test carried out on EN 1.4568 drawn wire (SEM observation)
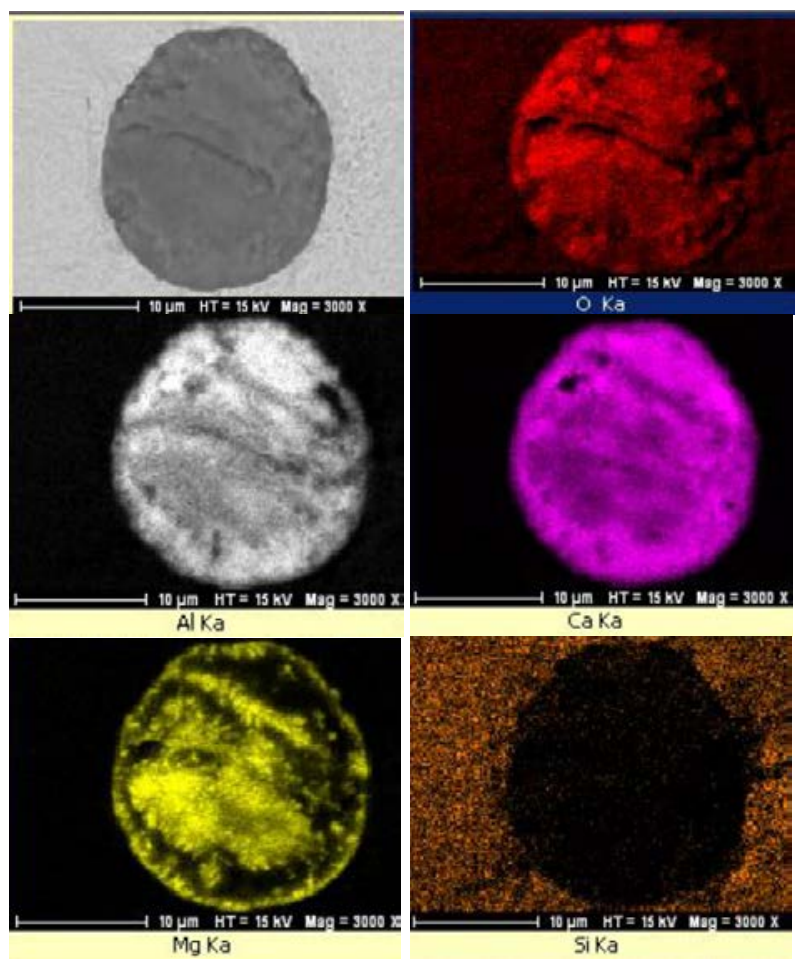

Fig. 12. Typical oxide inclusion as failure initiation during rotary bending test carried out on EN 1.4568 drawn wire; backscattered electron SEM image and X-Ray maps of the following chemical elements: Oxygen (red), Aluminium (white), Calcium (magenta), Magnesium (yellow) and Silicon (orange)

Beside their size, shape and location, the criticity of inclusions towards crack initiation is also linked to their relative plasticity at high temperatures and their relative thermal expansion to that of the stainless steel matrix. Indeed, both factors may promote local tensile residual stresses and micro-crack initiation at the inclusion/matrix interface $^{[1,6]}$. Values of such factors have been collected in table 4 for oxide inclusions and precipitates which have been observed in this study ${ }^{[6,12-14]}$. In this table, the plasticity index refers to the parameter defined by $\mathrm{R}$. KIESSLING $^{[6]}$ : the lower this index, the more critical the inclusion towards crack initiation. Comparing $A l N$ and $\mathrm{Al}-\mathrm{Ca}$ oxides for the same size and location, the figures suggest that $A l N$ precipitates are more likely to promote cracks than $\mathrm{Al}-\mathrm{Ca}$ oxides because of their angular shape and their lower thermal expansion coefficient at high temperatures. No value has been reported regarding the plasticity index of $A l N$ at high and room temperatures, but this index may be very low, close to zero, as it is the 
case for $\mathrm{Al}-\mathrm{Ca}$ oxides. Those observations agree with figure 10 which shows that failure initiations during rotary bending tests have occurred at $A l N$ in the large majority of the cases, and that oxide inclusions have been involved in failure initiations only when their size was greater than the maximum size of $A l N$ precipitates, i.e. oxides inclusions of diameter higher than $9 \mu \mathrm{m}$. Also, those results agree with the fact that oxide inclusions of diameter higher than $9 \mu \mathrm{m}$ are preferential sites for failure initiation in the sample. Furthermore, it can be noticed that according to WöHLER's curve shown in figure 9, oxide inclusions larger than $9 \mu \mathrm{m}$ are correlated with lower number of cycles at failure than Aluminium nitrides for a given value of maximum applied stress. When the subcutaneous area of the material is free of such inclusions and only oxides of lower diameter are present, failures initiate on largest Aluminium nitride precipitates.

The effect of inclusion or precipitate size on the fatigue limit can be substantiated by MURAKAMI's approach. Values of calculated endurance limit, via equation (2) in the case of $A l N$ or oxide inclusions of different sizes, have been collected in table 5. Firstly, calculated value of $\sigma_{\mathrm{D}}$ with equation (2) in the case of oxide inclusion maximum size (equal to $23 \mu \mathrm{m}$ ) is close to the experimental value found to be around $580 \mathrm{MPa}$. On the other hand, the presence of oxide inclusions of diameter $9 \mathrm{~mm}$ (the minimum diameter of oxide inclusions observed as failure initiation sites) leads to $\sigma_{\mathrm{D}}$ value very close to that obtained in the presence of maximum size $A l N$ precipitates. Finally, a $\sigma_{\mathrm{D}}$ increase of $100 \mathrm{MPa}$ could be expected by suppressing oxide inclusions with diameters higher than $9 \mu \mathrm{m}$.

Table 4. Values of mechanical and physical properties relative to inclusions or precipitates ${ }^{[6,12-14]}$

\begin{tabular}{|c|c|c|c|c|}
\hline & $\mathrm{C}_{12} \mathrm{~A}_{7}$ & $\mathrm{MgO}$ & AlN & $\begin{array}{l}\text { EN } \\
1.4568 \\
\text { grade }\end{array}$ \\
\hline $\mathrm{T}_{\text {fusion }}\left({ }^{\circ} \mathrm{C}\right)$ & 1455 & 2800 & 2200 & 1475 \\
\hline $\begin{array}{l}\text { Vickers Hardness } \\
(\mathrm{HV}) \text { at room } \mathrm{T}^{\circ}\end{array}$ & $\approx 900$ & $\approx 700$ & $\begin{array}{c}550 \text { to } \\
1150 \\
\end{array}$ & $\begin{array}{c}210 \text { to } \\
510\end{array}$ \\
\hline $\begin{array}{c}\text { Plasticity index }^{[6]} \\
\text { when } \mathrm{T}^{\circ} \in \\
{\left[800 ; 1400^{\circ} \mathrm{C}\right]}\end{array}$ & $\approx 0$ & 0 to 0,5 & & 1 \\
\hline $\begin{array}{c}\text { Thermal } \\
\text { expansion } \\
\text { between } 20 \text { and } \\
1000^{\circ} \mathrm{C}\left(\times 10^{-6} /{ }^{\circ} \mathrm{C}\right)\end{array}$ & 8 & 11,5 & 5 & 15 \\
\hline
\end{tabular}

Table 5. Values of fatigue limit $\sigma_{\mathrm{D}}$ calculated with different inclusion/precipitate sizes according to Murakami's work $^{[3]}$ (see equation (2))

\begin{tabular}{|c|c|c|c|}
\hline & AIN & \multicolumn{2}{|c|}{ oxyde } \\
\hline inclusion/precipitate shape & rectangular & \multicolumn{2}{|c|}{ round } \\
\hline inclusion/precipitate size $(\mu \mathrm{m})$ & $9 \times 7$ & $\varnothing 9$ & $\varnothing 23$ \\
\hline $\begin{array}{c}\text { inclusion/precipitate cross-section } \\
\text { area }\left(\mu \mathrm{m}^{2}\right)\end{array}$ & 63 & 63,5 & 415 \\
\hline $\begin{array}{c}\text { Vickers hardness }(\mathrm{Hv}) \\
\text { fatigue limit } \sigma_{\mathrm{D}}(\mathrm{MPa})\end{array}$ & 510 & 510 & 510 \\
\hline
\end{tabular}

An improvement of the fatigue limit of EN 1.4568 drawn wires also requires a reduction of the number of oxide inclusions larger than $9 \mu \mathrm{m}$. Figure 12 shows that those oxides are complex compounds with local areas enriched in $M g O$. Some investigations are under progress to explain the mechanism of their formation and hence propose modifications of the melting process to reduce their density and size.

Furthermore, improving the endurance limit of EN 1.4568 drawn wires requires also to lower the maximum size of Aluminium nitride precipitates, which is closely related to the Nitrogen content of the steel. In order to lower Nitrogen content, inerting during both melting and remelting processes should be improved.

\section{Conclusions and perspectives}

A methodology has been defined to study the influence of micro-cleanliness on the high cycle fatigue resistance of stainless steel wires or bars. It is based on MURAKAMI's work and rotary bending tests carried out up to 100 millions cycles. It has been applied to EN 1.4568 drawn wires of diameter equal to $3,60 \mathrm{~mm}$. The first trials have validated the setting of rotary bending equipment, the protocol for sample preparation and the calculation of test parameters.

Furthermore, they have shown that failures occurring during fatigue tests initiated preferentially at subcutaneous oxide inclusions of diameters higher than $9 \mu \mathrm{m}$. Those inclusions are complex and multiphase oxides, with high global contents of both $\mathrm{Al}_{2} \mathrm{O}_{3}$ and $\mathrm{CaO}$, but also containing $\mathrm{MgO}$ in locally variable amounts (from $0.5 \%$ up to $75 \%$ ) inside the same inclusion. Some investigations are under progress to explain the mechanism of their formation and hence propose modifications of the melting process to reduce their density and size. According to MURAKAMI's work, their suppression could lead to a $100 \mathrm{MPa}$ increase of the material's fatigue limit.

When the sample subcutaneous area is free of oxide inclusions whose diameters are higher than $9 \mu \mathrm{m}$, failures are seen to initiate at $A l N$ precipitates, whose sizes are lower than $9 \mu \mathrm{m}$, due to their angular shapes, and their relative low plasticity and thermal expansion at high temperatures in comparison to the stainless steel matrix. The size reduction of those AlN precipitates is mainly correlated to the steel Nitrogen content, also to the inerting conditions during both melting and remelting operations.

Authors' acknowledgements go to UGITECH's project team (S. ThÉvenet, R. Schneider, P. Trolliet, JC. Christin, A. LANGLet, K. BenchallaL), as well as persons involved in the development of remelted products (C. PhILIBERT, F. Bonifassi, R. Reynaud, A. Chèze, G. Pellissier, F. CAYER-BARrioz, N. SOCQUeT-Juglard, N. CRÉPELProvost). Other people from UGITECH R\&D are associated to this study (C. Bourgin, ML. MantouX, V. Marie, D. Juliano, D. Choulet, G. Dunand-Martin), as well as T. QuivY from Imphy drawing plant. Authors are also grateful to the supplier ZARIAN GmbH, represented by S. BlaetTerlein and B. LaUterbach. The authors want to thank Y. Follezou, JM. Dubois and F. Provent from S.F.G.P. for their contribution. 


\section{References}

1. H.P. Lieurade, Propriétés d'emploi des aciers - la rupture par fatigue des aciers, IRSID OTUA, Paris (1987)

2. T. ZouHAIR, Essais de fatigue par la méthode des "blocs programmes", PhD, INSA Lyon (1979)

3. Y. MuraKAmi, Metal fatigue : effects of small defects and nonmetallic inclusions, Elsevier (1993)

4. D. Rousseau, L. SÉRAPHIN, R. TRICOT, Internal Report $n^{\circ}$ 55793, Ugitech Research Center (1974)

5. H. NORDBERG, Swedish symposium on non-metallic inclusions in steel, Swedish Institute for Metal Research, Uddeholm (1981)

6. R. KIESSLING, Non-metallic inclusions in steel - Part III, The Iron and Steel Institute, (1968)

7. C. BERTRAND and al, Improving fatigue life of special steels by modifying their inclusion engineering, Final Report of European Com. Tech. Steel Research (2002)

8. Y. MuraKami, Journal of Research of the National Institute of Standards and Technology, 99, 4 (1994)

9. T. MANnInEN, Influence of cold-work on the elastic properties of austenitic stainless steels, Proceedings of the $7^{\text {th }}$ European Stainless Steel Conference ESSC 2011, Como, Italy, September 2011

10. M. LiBerT, Internal Analysis Report $n^{\circ} 16 \_159$, Ugitech Research Center, September 2016

11. M. Ayada, N. Takamura, Transactions of Japan Society of Spring Engineers, 1992, 37, p59-64 (1992)

12. Website of CTTC association (Centre de Transfert de Technologies Céramiques) : http://www.cttc.fr

13. P. KloceK, Handbook of Infrared Optical Materials, Library of Congress Cataloging in-publication data, NY, USA, 1991

14. C.E. CicutTI and al, Ironmaking and Steelmaking, 24, 2, p155-159 (1997) 